\title{
Evaluación de pastizales patagónicos con imágenes de satélites y de vehículos aéreos no tripulados
}

\author{
Marcos H. Easdale ${ }^{1, \bigotimes}$; Fernando Umaña ${ }^{2}$; Fernando Raffo ${ }^{\prime}$ C Clara Fariña ${ }^{1}$ \& \\ Octavio Bruzzone ${ }^{1}$ \\ ${ }^{1}$ Instituto de Investigaciones Forestales y Agropecuarias Bariloche (IFAB), INTA - CONICET. ${ }^{2}$ Instituto Nacional de \\ Tecnología Agropecuaria (INTA), E.E.A. Bariloche.
}

\begin{abstract}
Resumen. La evaluación de pastizales en regiones áridas y semiáridas es una herramienta clave tanto para planificar el manejo ganadero como para realizar diagnósticos ambientales. Si bien hay un consenso sobre la utilidad de dicha herramienta en la Patagonia, es muy costoso evaluar pastizales que tengan mucho detalle (grano) y, a la vez, cubrir amplias zonas o paisajes (extensión). Por esta razón, compatibilizar la resolución y la calidad de la información con la extensión espacial que se requiere para tomar decisiones en sistemas ganaderos todavía es un desafío operativo sin solución efectiva. En este sentido, en las últimas dos décadas, el uso de imágenes satelitales para evaluar pastizales fue en aumento. Los desarrollos asociados a la captura de imágenes mediante el uso de vehículos aéreos no tripulados (VANT) ofrecerían ventajas como complemento de información, dado que incrementan sensiblemente la resolución espacial. El objetivo de este trabajo fue clasificar ambientes de pastizal mediante el uso de imágenes satelitales y de VANT, y comparar sus respectivas contribuciones para evaluar pastizales en la Patagonia. En particular, se comparó la resolución espacial de una clasificación no supervisada de ambientes utilizando imágenes satelitales SPOT 7 e imágenes capturadas por un sensor óptico montado en un VANT. El estudio de los pastizales se podría potenciar con el uso de distintas fuentes de información de manera complementaria y accesible para el seguimiento de ambientes y para la planificación del manejo del pastoreo en ambientes muy heterogéneos en regiones áridas y semiáridas de la Patagonia, Argentina.
\end{abstract}

[Palabras clave: automatización, evaluación, imágenes satelitales, NDVI, VANT]

\begin{abstract}
Aвstract. Complementing satellites and unmanned aerial vehicles for rangeland assessment in Patagonia. Rangelands assessment in arid and semiarid regions is a key tool both for livestock management planning and environmental diagnoses. Even though there is a consensus on the utility of such tools, rangeland assessment with high detail (grain) while covering large areas or landscapes (extension) is too costly. Then, the compatibility between the resolution and quality of information and the spatial extent required to make decisions in livestock systems is still an operational challenge that has not found an effective solution. Thus, the use of satellite images for rangeland assessments in different environments has been growing steadily in the last two decades. The developments associated with the capture of images using unmanned aerial vehicles (UAVs) would offer many advantages as a complement to information, since they increase the spatial resolution. The aim of this work was to classify rangeland environments using satellite and UAV images and compare their respective contributions for rangeland assessments in Patagonia. In particular, spatial resolution of an unsupervised classification of rangeland environments using SPOT 7 satellite images and images captured by an optical sensor mounted on an UAV were compared. Rangeland assessment can be potentiated by the use of different sources of information in a more complementary and accessible way for environmental monitoring, and for a pastoral management planning in highly heterogeneous environments from arid and semiarid regions of Patagonia, Argentina.
\end{abstract}

[Keywords: automation, remote sensing, NDVI, UAV]

\section{INTRODUCCIÓN}

La evaluación de pastizales en regiones áridas y semiáridas es una herramienta clave tanto para planificar un manejo ganadero sustentable en sistemas de producción extensivos como para evaluar ambientales y seguir procesos complejos como la desertificación y el impacto del cambio climático. Sin embargo, a pesar de muchos esfuerzos tanto en el sector público como privado, en la Patagonia se la ha usado de forma intermitente y aún no está generalizada en términos operativos debido a múltiples factores (Ormaechea et al. 2019). Si bien las causas de esta situación no están muy estudiadas, se podría mencionar que tomar decisiones en función de las evaluaciones prediales de pastizal no genera resultados económicos en el corto plazo, sumado a la relativa baja importancia otorgada a esta herramienta en comparación con otras tecnologías productivas. Entre las 
posibles causas también se pueden mencionar restricciones de infraestructura para una planificación óptima del pastoreo, escasez de profesionales formados en la temática e, incluso, ciertas limitantes que poseen todavía los métodos disponibles. En referencia a las metodologías, uno de los problemas principales aún no resuelto es que existe un compromiso entre el costo (económico y en tiempo) de obtener información de alta resolución y calidad, y la superficie y el período de tiempo total abarcados para la toma de decisiones. En otras palabras, dadas las grandes extensiones de los establecimientos ganaderos en la Patagonia, es muy costoso realizar evaluaciones de pastizal que tengan mucho detalle (grano) y que, a la vez, cubran una amplia extensión espacial asociada a un predio, un cuadro de manejo o unidad de paisaje (extensión). Esto genera que la evaluación no logre discriminar y analizar acabadamente la heterogeneidad espacial hacia el interior de las unidades de paisaje o comunidades de vegetación, enmascarando procesos de sobreuso y degradación, o incluso, de subutilización.

El problema de compatibilizar detalle de información con extensión espacial en las evaluaciones de pastizal se resolvió parcialmente con el uso complementario de diferentes métodos. Uno de los principales avances recientes en la materia, y de crecimiento sostenido en las últimas dos décadas, viene de la mano del uso de imágenes satelitales para evaluar la estructura, el funcionamiento y la productividad de pastizales en distintos ambientes (e.g., Paruelo et al. 1997; Jobbágy et al. 2002; Paruelo et al. 2004; Kurtz et al. 2010; Gaitán et al. 2013). En este sentido, uno de los métodos disponibles para la evaluación de pastizal en la Patagonia utiliza primero información satelital como base para clasificar ambientes o unidades de paisaje. Luego, esta información se valida y complementa con datos de mayor resolución basados en relevamientos a campo, usando transectas o stands de relevamiento, en sitios predefinidos como representativos de distintas unidades de paisaje o comunidades vegetales (e.g., Borrelli et al. 2001; Elissalde et al. 2002; Siffredi et al. 2013). Esta metodología se basa en el concepto de representatividad de un sitio. En consecuencia, la información obtenida a campo se extrapola a toda la unidad de paisaje, dado el alto costo de abarcar toda la superficie manteniendo una resolución alta en los datos. Otro método disponible estima la receptividad ganadera como el cociente entre la disponibilidad forrajera y el consumo animal individual (Golluscio et al. 2009). Dichas estimaciones se realizan mediante cálculos de la productividad primaria neta aérea (PPNA) a partir de datos de imágenes satelitales como, por ejemplo, las del sensor MODIS (Moderate Resolution Image Spectroradiometer), que permite analizar series de tiempo interanuales (e.g., período 2000-2019) y cubrir grandes extensiones con menor costo (Golluscio et al. 2010; Easdale and Aguiar 2012). Una limitante de este método es que no discrimina composición florística y cobertura vegetal, que a escalas de mayor detalle constituyen factores relevantes para determinar con mayor precisión el componente forrajero (Easdale and Aguiar 2012). A su vez, el área que representa el píxel de información de dichas imágenes MODIS (6.25 ha) es mayor al necesario para discriminar la estructura de la vegetación en pastizales de la Patagonia.

Recientemente, los desarrollos asociados a la captura de imágenes mediante el uso de vehículos aéreos no tripulados (VANT) podrían ofrecer muchas ventajas en el estudio de pastizales, especialmente en zonas con manejo ganadero extensivo como las regiones áridas y semiáridas. Entre las principales ventajas se destacan el desarrollo rápido y de bajo costo del equipo, la flexibilidad en las condiciones de vuelo, la periodicidad de las misiones y una mayor resolución espacial (Rango et al. 2006, 2009; Hardin and Jensen 2011). De todas maneras, si bien se resalta su potencialidad, no se cuenta aún con evaluaciones y análisis de información en ambientes patagónicos.

El objetivo de este trabajo fue clasificar ambientes de pastizal mediante el uso de imágenes con alta y muy alta resolución espacial, y comparar sus respectivas contribuciones para la evaluación de pastizales en la Patagonia. En particular, se comparó la resolución espacial en la clasificación de ambientes de pastizales utilizando imágenes satelitales multiespectrales SPOT 7, como referencia de una alta resolución espacial (2.25 $\mathrm{m}^{2}$ ), e imágenes multiespectrales capturadas por un sensor óptico montado en un vehículo aéreo no tripulado (VANT), como referencia de muy alta resolución espacial $\left(0.0049 \mathrm{~m}^{2}\right)$. La complementación entre distintas fuentes de información es discutida en términos de su potencial para desarrollar evaluaciones de pastizal que discriminen la heterogeneidad de la vegetación a distintas escalas, orientada a la planificación de un pastoreo que la considere de manera explícita. 


\section{MATERIALES y MÉTODOS}

\section{Área de estudio}

El estudio se realizó en la Estancia Fortín Chacabuco, provincia de Neuquén (Figura 1). El área de estudio fue $\sim 50$ ha e incluyó un humedal (localmente denominado mallín) y zonas aledañas de estepa graminosa y graminosa-arbustiva. El mallín está conformado por una zona central con mayor humedad y presencia de agua en superficie, dominado por vegetación de junco (Juncus balticus), con presencia de Poa pratensis, Trifolium repens, Dactylis glomerata y Taraxacum officinale, y una zona periférica con menor humedad dominada por Festuca pallescens, con presencia dispersa de Berberis spp. y Discaria trinervis. La estepa circundante se caracteriza por una dominancia de Pappostipa speciosa y Festuca spp., con presencia de arbustos de Azorella prolifera.

\section{Fuente de datos}

Imágenes satelitales. Se utilizaron dos fuentes de imágenes satelitales. Por un lado, para los estudios espaciales se utilizó una imagen satelital de alta resolución multiespectral de 4 bandas (rojo, verde, azul e infrarrojo) de
SPOT 7 (producto PMS fusión de 4 bandas). La captura de datos está referenciada con fecha 21 de noviembre de 2017, con una resolución de píxel de $1.5 \mathrm{~m}\left(2.25 \mathrm{~m}^{2}\right)$, proporcionada por la Comisión Nacional de Actividades Espaciales (CONAE).

Imágenes de cámaras montadas en un vehículo aéreo no tripulado (VANT). Se utilizó un VANT de ala fija de emprendimientos Mapaer, modelo Matungo. Su masa es de 2 $\mathrm{kg}$ y la estructura de polipropileno expandido (EPP, expanded polypropylene). El mismo estuvo bajo el control de vuelo del software libre HKPilot32, desarrollado para VANT. Se usó una batería LiPo de 3 celdas, de $5000 \mathrm{mAh}$. En la estructura del VANT se montaron dos cámaras Mapir (modelo Survey2), ambas con una resolución de 16 megapíxeles. Una cámara se usó para capturar imágenes en el espectro visible, con tres canales (rojo, verde y azul o RGB), en el rango 440 - $640 \mathrm{~nm}$. La otra cámara se utilizó para capturar imágenes en un único canal asociado al espectro del infrarrojo cercano (NIR), centrado en $850 \mathrm{~nm}$.

Captura de imágenes y procesamiento de datos de imagen VANT. El vuelo para la captura de imágenes se realizó el día 7 de noviembre de 2017, a una altura de $200 \mathrm{~m}$
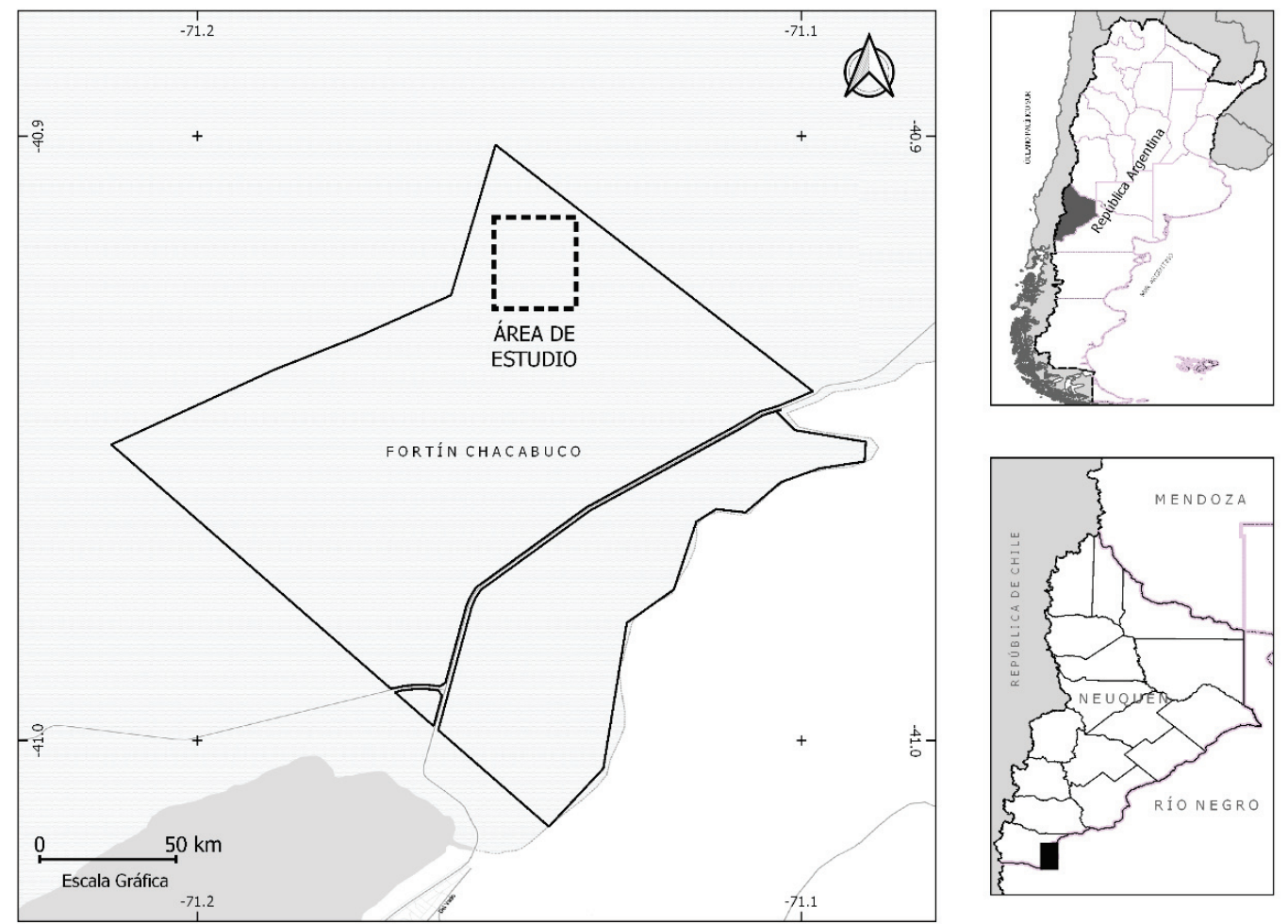

Figura 1. Área de estudio. Mallín Frisón, ubicado en Estancia Fortín Chacabuco, provincia de Neuquén.

Figure 1. Study area. Mallín Frisón, suited in Fortín Chacabuco ranch, Neuquén province. 
s. n. m. En total se capturaron 303 imágenes con la cámara NIR y 321 con la cámara RGB. La resolución del píxel fue de $7 \times 7 \mathrm{~cm}$ $\left(0.0049 \mathrm{~m}^{2}\right)$. A las imágenes capturadas por ambas cámaras se les efectuaron correcciones radiométricas (calibradas con un patrón de reflectancia utilizado antes del vuelo) y correcciones geométricas para luego generar un ortomosaico, respectivamente. Luego, ambas imágenes se combinaron para obtener una única escena multiespectral, compuesta por 4 bandas: rojo, verde, azul e infrarrojo cercano.

Rectificación de la imagen VANT con Spot 7. Para corregir cualquier leve desfasaje espacial entre la imagen SPOT 7 y el ortomosaico generado con imágenes VANT se procedió a rectificar el ortomosaico. Este proceso se realizó mediante un modelo polinomial (o transformación polinomial de segundo grado) que se obtiene a partir de un conjunto de pares de puntos de control de ambas imágenes. Se usaron 25 puntos de control; para seleccionarlos se identificaron elementos del terreno fácilmente localizables, como, por ejemplo, cruces de caminos, límites de alambrados, aguadas y otros puntos singulares. La elección de estos puntos se realizó considerando la resolución espacial de ambas imágenes. Como resultado de la rectificación, ambas imágenes VANT y SPOT 7 quedaron perfectamente solapadas y coincidentes en el espacio.

Clasificación de ambientes en imágenes VANT y SPOT 7. La clasificación de ambientes se realizó de manera no supervisada, para lo cual el algoritmo clasificador no necesita de más información que las bandas que integran la escena o imagen a clasificar y algunos parámetros que limiten el número de clases. Este método de clasificación se fundamenta en la búsqueda de clases con suficiente separabilidad de la señal espectral, que permita diferenciar elementos o clases mediante la búsqueda iterativa de valores homogéneos. Para ello se utilizó el algoritmo ISODATA (Interactive Self-Organizing Data Analysis Technique Algorithm) (Duda and Hart 1973). Los parámetros utilizados para la clasificación en cada escena, fueron los siguientes: 1) diez clases a obtener en total, 2) umbral de convergencia de 0.950, y 3) exclusión de valores igual a cero.

Una vez obtenida la clasificación con diez clases en cada escena, las mismas fueron interpretadas y reagrupadas de acuerdo a criterios de cobertura y estructura de la vegetación basados en el conocimiento y relevamientos a campo previos en el área de estudio. Este paso permitió reagrupar clases homogéneas, considerando el procesamiento de ambas escenas. Finalmente, se obtuvo una clasificación compuesta por siete clases. Se utilizaron tres píxeles correspondientes a imágenes MODIS (superficie de 6.25 ha) como límites de áreas para comparar la clasificación de ambientes obtenidas con SPOT 7 y VANT, respectivamente. Los tres píxeles se ubicaron en zonas de la cuenca alta, media y baja del área de estudio. Teniendo en cuenta las clasificaciones no supervisadas, se seleccionaron píxeles con una composición diversa y contrastante en términos de los pastizales presentes (e.g., mallín central y periférico, estepa). Una imagen de MODIS que aglomeraba dichos píxeles fue re-proyectada al sistema de referencia de coordenadas de la imagen SPOT 7 (UTM WGS 84 Zona 19S), para luego realizar los cortes espaciales en ambas escenas (VANT y SPOT 7). Por último, en ambas imágenes y para cada píxel se calculó la cantidad de píxeles por clase a fin de estimar la superficie y el porcentaje de cobertura de cada clase en las clasificaciones obtenidas a partir de cada tipo de imagen.

\section{Resultados}

La clasificación no supervisada de las escenas VANT y SPOT 7, consolidada en 7 clases que identificaron distintos ambientes del área de estudio, configuraron un patrón espacial con algunas diferencias a escala de paisaje (Figuras 2 y 3). Las clases obtenidas refirieron a pastizal de estepa graminosa y graminosa-arbustiva (clases 5, 6 y 7), un ambiente ecotonal entre el humedal y la estepa (clase 4), mallín periférico graminoso (clase 3), mallín central (clase 2) y ambientes de alta humedad asociados a cursos de agua (clase 1). A escala de paisaje, la delimitación del área del humedal respecto del área esteparia adyacente fue similar. Las mayores diferencias se encontraron en el detalle de los límites entre las clases y las respectivas estimaciones en términos de superficie, como consecuencia de la diferencia en la resolución espacial entre escenas.

La diferencia en la clasificación de ambientes se puede observar en determinadas zonas seleccionadas para obtener mayor detalle, en este caso ejemplificado con los píxeles seleccionados usando imágenes MODIS. Por ejemplo, en el Píxel 1, la proporción 


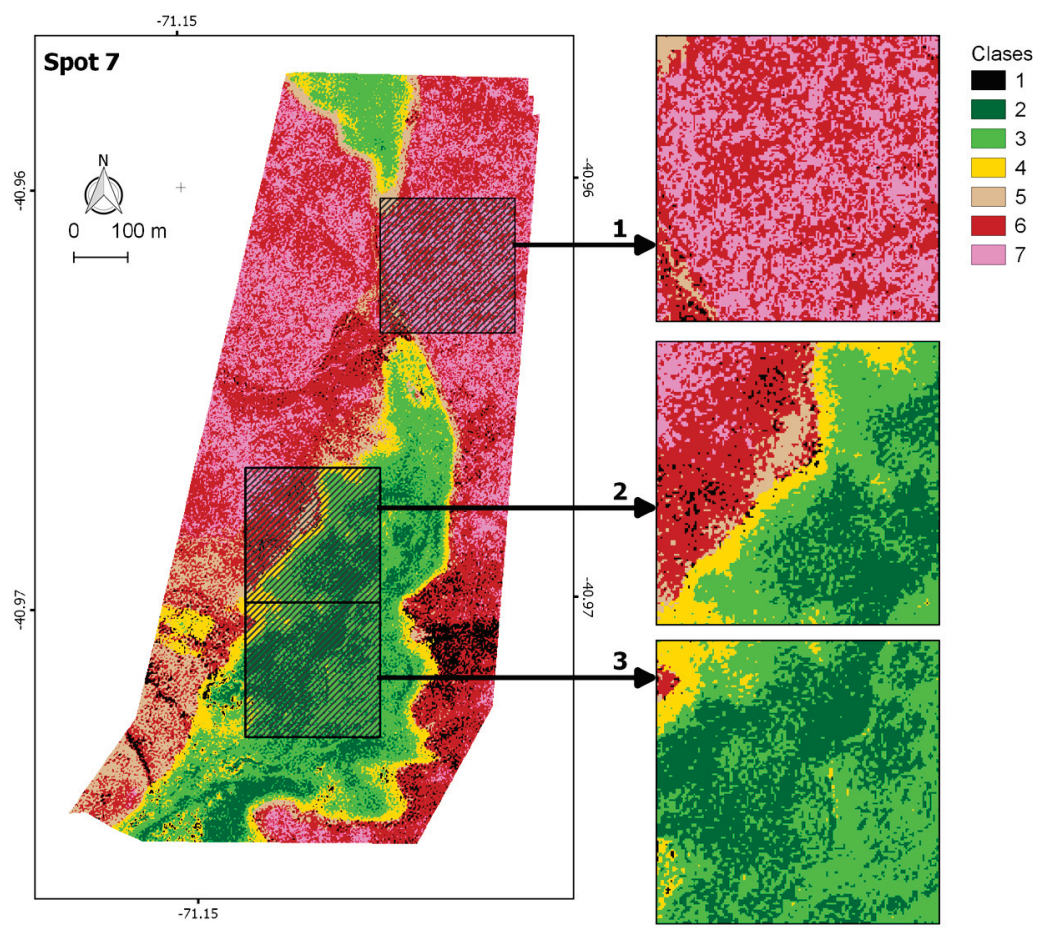

Figura 2. Clasificación no supervisada de una imagen multiespectral de SPOT 7 (fecha: 21 de noviembre 2017). Píxel con resolución espacial de $1.5 \mathrm{~m}$. Se identifican las áreas correspondientes a tres píxeles de MODIS (250 m): 1) Píxel 1, seleccionado por la dominancia de estepa graminosa y su referencia a la alta cuenca, 2) Píxel 2, seleccionado por su conformación que combina mallín periférico y estepa, y su referencia a una cuenca media, y 3) Píxel 3, seleccionado por la dominancia de mallín central y su referencia a una cuenca baja. Referencia de las clases: ambientes de alta productividad asociados a cursos de agua (clase 1), mallín central (clase 2), mallín periférico graminoso (clase 3), ambiente ecotonal entre el humedal y la estepa (clase 4), y pastizales de estepa graminosa y graminosa-arbustiva (clases 5, 6 y 7).

Figura 2. Unsupervised classification of a multispectral image of SPOT 7 (date November 21, 2017). Pixel with a spatial resolution of $1.5 \mathrm{~m}$. The areas correspond to three selected MODIS pixels (250 m): 1) Pixel 1, selected due to the dominance of grass steppe and its reference to the high basin, 2) Pixel 2, selected for its combination of peripheral wetland and steppe, and its reference to a middle basin, and 3) Pixel 3, selected due to the dominance of a wetland and its reference to a low basin. Classes references: high productivity environments associated with water streams (class 1 ), central prairie (class 2), peripheral prairie (class 3), wetland-steppe ecotone (class 4), and grass and grass-shrubs steppes (classes 5, 6 and 7).

Tabla 1. Superficie en hectáreas y porcentaje relativo ocupado por cada clase obtenida para el área del píxel 1 (dominado por estepa graminosa), píxel 2 (conformado por una combinación de mallín periférico y estepa), y píxel 3 (dominado por mallín central), para la clasificación realizada sobre la imagen a) VANT (ver Fig. 3) y b) SPOT 7 (ver Fig. 2), respectivamente. Se presenta la diferencia (positiva o negativa) en el área estimada con la imagen SPOT respecto de la imagen VANT, para cada clase y cada píxel respectivamente. Referencia de clasesen Fig. 2.

Table 1. Area in hectares and relative percentage for each obtained class for the area of pixel 1 (dominated by grass steppes), pixel 2 (dominated by peripheral wetland and grass steppes), and pixel 3 (dominated by a wetland), for the classification made on the image a) UAV (see Fig. 3), and b) SPOT 7 (see Fig. 2), respectively. It is presented the difference (positive or negative) in the area estimated with the SPOT image with respect to the UAV image, for each class and each pixel respectively. Classes references in Fig. 2.

\begin{tabular}{|c|c|c|c|c|c|c|c|c|c|c|c|c|c|c|c|}
\hline \multirow{3}{*}{ Clases } & \multicolumn{5}{|c|}{ PIXEL \# 1} & \multicolumn{5}{|c|}{ PIXEL \# 2} & \multicolumn{5}{|c|}{ PIXEL \# 3} \\
\hline & \multicolumn{2}{|c|}{ VANT } & \multicolumn{2}{|c|}{ SPOT } & \multirow{2}{*}{$\begin{array}{l}\text { Diferencia } \\
\text { (ha) }\end{array}$} & \multicolumn{2}{|c|}{ VANT } & \multicolumn{2}{|c|}{ SPOT } & \multirow{2}{*}{$\begin{array}{l}\text { Diferencia } \\
\text { (ha) }\end{array}$} & \multicolumn{2}{|c|}{ VANT } & \multicolumn{2}{|c|}{ SPOT } & \multirow{2}{*}{$\begin{array}{l}\text { Diferencia } \\
\text { (ha) }\end{array}$} \\
\hline & $\%$ & $\begin{array}{c}\text { Area } \\
\text { (ha) }\end{array}$ & $\%$ & $\begin{array}{c}\text { Area } \\
\text { (ha) }\end{array}$ & & $\%$ & $\begin{array}{c}\text { Area } \\
\text { (ha) }\end{array}$ & $\%$ & $\begin{array}{c}\text { Area } \\
\text { (ha) }\end{array}$ & & $\%$ & $\begin{array}{c}\text { Area } \\
\text { (ha) }\end{array}$ & $\%$ & $\begin{array}{l}\text { Area } \\
\text { (ha) }\end{array}$ & \\
\hline 1 & 0 & $<0,001$ & 0,65 & 0,041 & 0,041 & 0,74 & 0,046 & 1,8 & 0,113 & 0,067 & 7,86 & 0,491 & 0,17 & 0,011 & $-0,481$ \\
\hline 2 & $<0,001$ & $<0,001$ & 0 & 0 & $<0,001$ & 20,65 & 1,292 & 22,05 & 1,384 & 0,092 & 73,15 & 4,574 & 45,15 & 2,85 & $-1,725$ \\
\hline 3 & 0 & $<0,001$ & 0 & 0 & $<0,001$ & 26,46 & 1,655 & 31,47 & 1,975 & 0,32 & 12,61 & 0,789 & 48,86 & 3,084 & 2,296 \\
\hline 4 & 7,46 & 0,466 & 2,47 & 0,157 & $-0,31$ & 22,01 & 1,377 & 5,18 & 0,325 & $-1,052$ & 4,21 & 0,263 & 0,12 & 0,007 & $-0,256$ \\
\hline 5 & 3,22 & 0,201 & 0 & 0 & $-0,201$ & 10,91 & 0,683 & 9,78 & 0,614 & $-0,069$ & 2,09 & 0,131 & 5,22 & 0,329 & 0,199 \\
\hline 6 & 65,81 & 4,115 & 52,54 & 3,337 & $-0,779$ & 18,7 & 1,17 & 24,6 & 1,544 & 0,374 & 0,07 & 0,005 & 0,49 & 0,031 & 0,026 \\
\hline 7 & 23,51 & 1,47 & 44,34 & 2,816 & 1,345 & 0,53 & 0,033 & 5,11 & 0,321 & 0,288 & 0,01 & 0,001 & 0 & 0 & $-0,001$ \\
\hline Total & 100 & 6,254 & 100 & 6,35 & 0,097 & 100 & 6,256 & 100 & 6,275 & 0,02 & 100 & 6,254 & 100 & 6,313 & 0,059 \\
\hline
\end{tabular}




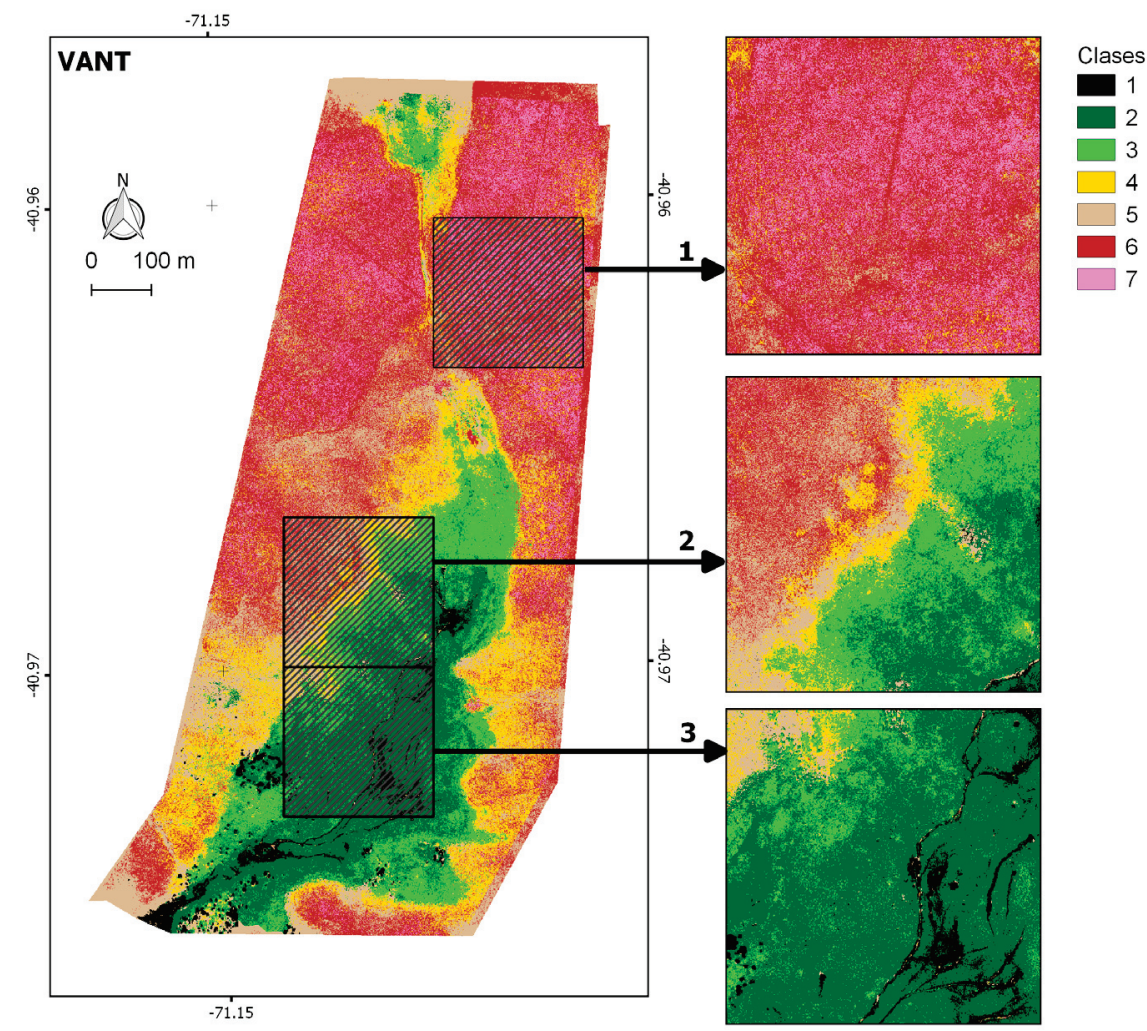

Figura 3. Clasificación no supervisada del ortomosaico construido con imágenes capturadas con una cámara multiespectral montada en un vehículo aéreo no tripulado (VANT) (fecha 07 de noviembre de 2017). Píxel con resolución espacial de $7 \mathrm{~cm}$. Se identifican las áreas correspondientes a tres píxeles de MODIS (250 m): 1) Píxel 1, seleccionado por la dominancia de estepa graminosa y su referencia a la alta cuenca, 2) Píxel 2, seleccionado por su conformación que combina mallín periférico y estepa, y su referencia a una cuenca media, y 3) Píxel 3, seleccionado por la dominancia de mallín central y su referencia a una cuenca baja. Referencia de clases en la Figura 2.

Figura 3. Unsupervised classification of the ortomosaic built with images captured with a multispectral camera mounted on an unmanned aerial vehicle (UAV) (date November 07, 2017). Pixel with a spatial resolution of $7 \mathrm{~cm}$. The areas correspond to three selected MODIS pixels $(250 \mathrm{~m})$ : 1) Pixel 1, selected due to the dominance of grass steppe and its reference to the high basin, 2) Pixel 2, selected for its combination of peripheral prairie and steppe, and its reference to a middle basin, and 3) Pixel 3, selected due to the dominance of a wetland and its reference to a low basin. Classes references in Figure 2.

total de las clases asociadas a pastizal de estepa fue similar, pero con diferencias en las proporciones relativas de las clases que la describieron, en particular entre clases 6 y 7 (Tabla 1). En el Píxel 2, la escena SPOT 7 registró 3.36 ha de ambiente de mallín central y periférico (clases 2 y 3 , Tabla 1 ), mientras que VANT registró una superficie menor, en torno a 2.95 ha. En este caso, la principal diferencia se registró en la clase 4 , con una diferencia de un poco más de 1 ha a favor de la escena VANT (Tabla 1). Finalmente, en la descomposición del Píxel 3, ambas imágenes estimaron una superficie similar conformada por área de mallín (5.93 ha con SPOT 7, y 5.85 ha con VANT) (Tabla 1). Sin embargo, la imagen VANT permitió discriminar tres zonas: una, asociada a los cursos principales de agua con una superficie cercana a 0.5 ha, y las otras dos, a zonas de mallín central y periférico; el de mayor área correspondió a mallín central (4.5 ha) (Tabla 1). Por otro lado, la imagen SPOT 7 discriminó dos zonas asociadas a mallín central y periférico, estimando una mayor superficie de la clase asociada a mallín periférico (3.08 ha) y no logró discriminar el microambiente de mayor humedad con vegetación con alta actividad fotosintética (clase 1, Tabla 1).

\section{DISCUSIÓN}

Las características diferenciales de los datos capturados por sensores ópticos montados en satélites y en VANT ofrecen una complementariedad alta debido al tipo de información que pueden brindar. Por un lado, los patrones de clasificación de ambientes mediante escenas de SPOT 7 y de VANT fueron similares a escala de paisaje (Figuras 2 y 3), aunque se registraron diferencias en 


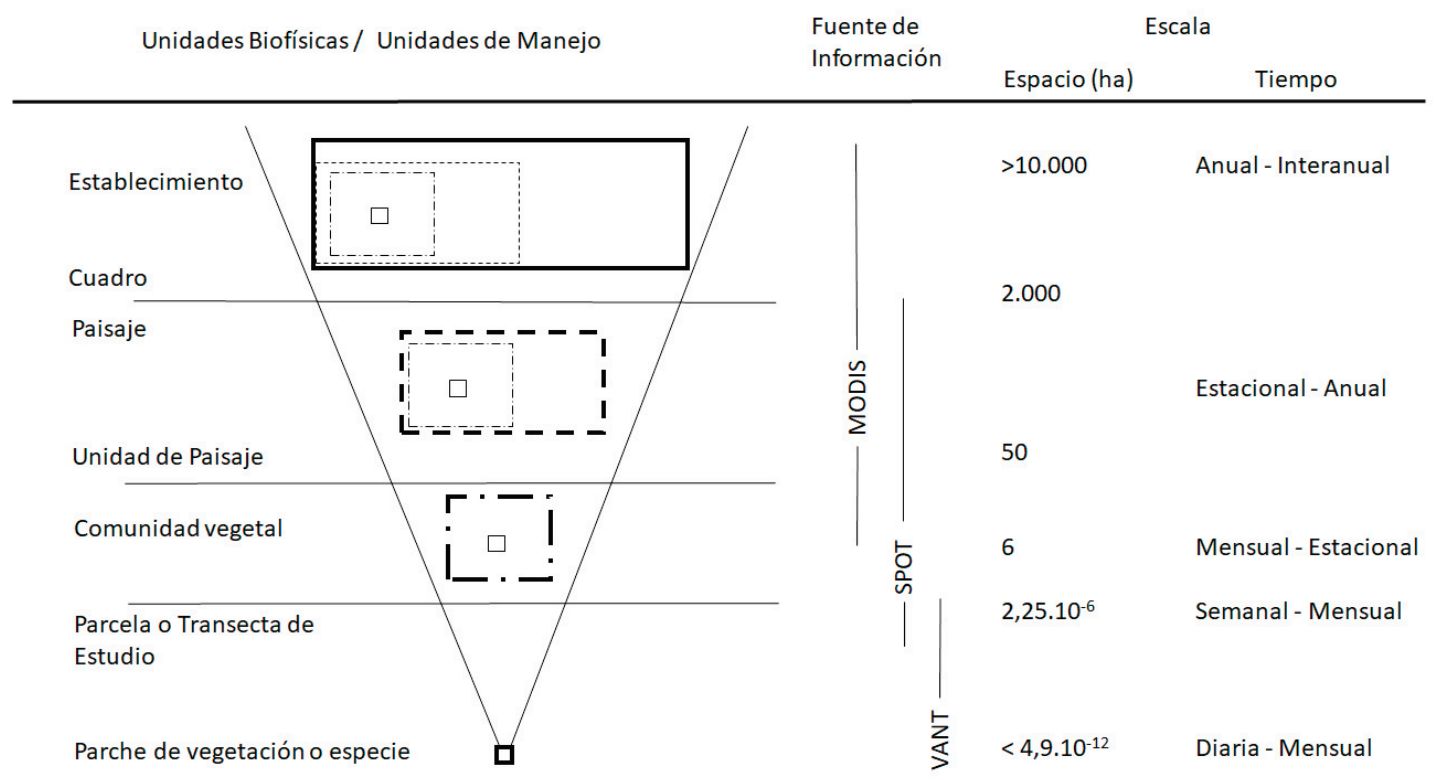

Figura 4. Esquema conceptual sobre la complementación de información provista por imágenes satelitales y VANT, basada en la escala espacial y temporal en la que podrían ofrecer mayores ventajas, en relación con unidades biofísicas o de manejo de sistemas ganaderos en contextos de Patagonia.

Figura 4. Conceptual framework on the complementation of the information provided by satellite images and UAV, based on the spatial and temporal scales in which they can offer greater advantages, in relation to biophysical or management units for livestock systems in Patagonian contexts.

las delimitaciones entre las clases y en la capacidad de identificar microambientes como los de vegetación asociada a los cursos de agua (Tabla 1). Estos resultados sugieren una potencialidad para clasificar ambientes a escala de subpíxeles, en sitios seleccionados o priorizados para su seguimiento por razones de manejo ganadero, como podría ser una alta productividad forrajera en áreas de mallines. Por ejemplo, sería posible estimar con precisión la biomasa y la calidad forrajera determinada por diferencias en comunidades vegetales a través de imágenes VANT, que no pueden ser discriminadas de forma adecuada con imágenes satelitales de alta resolución (e.g., Píxel 3, Tabla 1). La Figura 4 sintetiza una propuesta de complementación de imágenes satelitales y VANT usadas en este estudio, basada en la escala espacial y temporal en la que podrían ofrecer mayores ventajas en contextos de la Patagonia. En primer lugar, las imágenes satelitales permiten contar con datos con resolución valiosa a escala de paisaje y establecimiento, y para ventanas de tiempo interanuales. Por otro lado, las imágenes VANT permiten incrementar la resolución espacial de los datos y, con ello, la capacidad de otorgar mayor detalle al delimitar ambientes y estudios ecológicos (Anderson and Gaston 2013), lo cual fue corroborado en este estudio. En particular, la mayor contribución de datos obtenidos con VANT refiere a escalas de comunidades y parches de vegetación, y momentos específicos del ciclo anual (Figura 4). Por ejemplo, futuros estudios podrían avanzar en tipificar parches de vegetación y caracterizar su geometría de manera espacialmente explícita, como insumo para estimaciones de biomasa y calidad forrajera. A su vez, se podría aprovechar la clasificación de ambientes con límites más precisos e identificar cambios espaciales dentro de unidades de paisaje o comunidades vegetales, así como cambios temporales vinculados a las variaciones estacionales o interanuales en la actividad fotosintética de la vegetación, la fenología y su relación con la disponibilidad de agua. Esta información sería útil para complementar otros estudios, como los de patrones de pastoreo de animales a escala de paisaje mediante geo-posicionamiento (Morales and Ellner 2002) o estudios de intensidad de pastoreo espacialmente heterogénea. Por último, las imágenes obtenidas con VANT se podrían usar para discriminar la estructura de la vegetación de un píxel como el de MODIS, en los sitios clave identificados para realizar un seguimiento temporal detallado de ciertos ecosistemas y como soporte de decisiones de manejo de pastoreo en ambientes muy heterogéneos, como los patagónicos. 


\section{CONCLUSIONES}

La evaluación de pastizales en términos estructurales y funcionales en la Patagonia debería avanzar hacia el desarrollo de propuestas que complementen diferentes fuentes de información de sensores remotos (satelitales y VANT) y sus respectivas ventajas en términos de resolución espacial y temporal. La estrategia de complementación de información podría considerar la utilización de imágenes satelitales para clasificar y caracterizar ambientes a escala de predio y cuadros de manejo ganadero. Luego, la identificación de zonas representativas en cada unidad de paisaje (e.g., estepas graminosas, estepas arbustivo-graminosas, zonas de mallines húmedos y de mallines subhúmedos) permitiría seleccionar sitios de evaluación y seguimiento más detallado basado en el análisis de series de tiempo interanuales (representado en este trabajo por un píxel de imágenes MODIS).Usar información de VANT permitiría caracterizar en detalle la estructura de la vegetación en dichos sitios seleccionados, a nivel de subpíxel. Este avance debería ir acompañado de investigaciones que permitan mejorar progresivamente en la interpretación de una mayor resolución de la información de los pastizales, integrando datos de sensores remotos con datos de campo.

AgradeCimientos. Este estudio fue financiado por INTA (PRET-1281103 y 1281101) y por The Nature Conservancy (TNC), en el marco del convenio de vinculación tecnológica \#24700. La captura de imágenes fue realizada con un VANT modelo Matungo, de Emprendimiento Mapaer y el apoyo a campo de Martín Garrett y Lucas Muñoz, a quienes agradecemos su colaboración. Agradecemos especialmente a Gustavo Iglesias, Gwen Hulssege y Nicolás Rodríguez por su excelente predisposición y colaboración para ejecutar este estudio en la Estancia Fortín Chacabuco, Neuquén.

\section{REFERENCIAS}

Aguiar, M. R., and O. E. Sala. 1999. Patch structure, dynamics and implications for the functioning of arid ecosystems. Trends in Ecology and Evolution 14:273-277. https:/ /doi.org/10.1016/S0169-5347(99)01612-2.

Anderson, K., and K. J. Gaston. 2013. Lightweight unmanned aerial vehicles will revolutionize spatial ecology. Frontiers in Ecology and the Environment 11(3):138-146. https://doi.org/10.1890/120150.

Borrelli, P., G. Oliva, A. Cibils, P. Rial, and L. González. 2001. Evaluación de pastizales. Pp. 161-182 en P. Borrelli y G. Oliva (eds.). Ganadería ovina sustentable en la Patagonia Austral. Tecnología de Manejo Extensivo. PRODESAR, INTA-GTZ.

Duda, T., and P. Hart. 1973. Pattern classification and scene analysis. New York, John Wiley and Sons. Pp. 189.

Easdale, M. H., and M. R. Aguiar. 2012. Regional forage production assessment in arid and semi-arid rangelands-A step towards social-ecological analysis. Journal of Arid Environments 83:35-44. https://doi.org/10.1016/ j.jaridenv.2012.03.002.

Elissalde, N., J. Escobar, and V. Nakamatsu. 2002. Inventario y evaluación de pastizales naturales de la zona árida y semiárida de la Patagonia. Programa de acción nacional de lucha contra la desertificación. Cooperación técnica argentino-alemana, Convenio SA y DS- INTA- GTZ. Pp. 45.

Gaitán, J. J., D. Bran, G. E. Oliva, G. Ciari, V. Nakamatsu, J. Salomone, D. Ferrante, G. Buono, V. Massara, G. Humano, and D. Celdrán. 2013. Evaluating the performance of multiple remote sensing indices to predict the spatial variability of ecosystem structure and functioning in Patagonian steppes. Ecological Indicators 34:181-191. https://doi.org/ 10.1016/j.ecolind.2013.05.007.

Golluscio, R. A., V. A. Deregibus, and J. M. Paruelo. 1998. Sustainability and range management in the Patagonian steppes. Ecología Austral 8:265-284.

Golluscio, R. 2009. Receptividad ganadera: marco teórico y aplicaciones prácticas. Ecología Austral 19:215-232.

Golluscio, R. A., M. E. Román, A. Cesa, D. Rodano, H. Bottaro, M. I. Nieto, A. Betelú, and L. A. Golluscio. 2010. Aboriginal settlements of arid Patagonia: Preserving bio-or sociodiversity? The case of the Mapuche pastoral Cushamen Reserve. Journal of Arid Environments 74(10):1329-1339. https://doi.org/10.1016/j.jaridenv.2010.05.012.

Green, K., D. Kempka, and L. Lackey. 1994. Using remote sensing to detect and monitor land-cover and land-use change. Photogrammetric Engineering and Remote Sensing 60(3):331-337.

Hardin, P. J., and R. R. Jensen. 2011. Small-scale unmanned aerial vehicles in environmental remote sensing: Challenges and opportunities. GIScience and Remote Sensing 48(1):99-111. https://doi.org/10.2747/1548-1603.48.1.99. https:// doi.org/10.2747/1548-1603.48.1.1.

Huang, S., and F. Siegert. 2006. Land cover classification optimized to detect areas at risk of desertification in North China based on SPOT VEGETATION imagery. Journal of Arid Environments 67(2):308-327. https: / doi.org/10.1016/ j.jaridenv.2006.02.016.

Hung, W. C., Y. C. Chen, and K. S. Cheng. 2010. Comparing landcover patterns in Tokyo, Kyoto, and Taipei using ALOS multispectral images. Landscape and Urban Planning 97(2):132-145. https:/ /doi.org/10.1016/j.landurbplan .2010.05.004.

Jobbágy, E. G., O. E. Sala, and J. M. Paruelo. 2002. Patterns and controls of primary production in the Patagonian steppe: 
a remote sensing approach. Ecology 83(2):307-319. https://doi.org/10.1890/0012-9658(2002)083[0307:PACOPP]2.0.CO;2. https://doi.org/10.2307/2680015.

Joyce, K. E., S. E. Belliss, S. V. Samsonov, S. J. McNeill, and P. J. Glassey. 2009. A review of the status of satellite remote sensing and image processing techniques for mapping natural hazards and disasters. Progress in Physical Geography 33(2):183-207. https:/ /doi.org/10.1177/0309133309339563.

Kurtz, D. B., J. Schellberg, and M. Braun. 2010. Ground and satellite-based assessment of rangeland management in sub-tropical Argentina. Applied Geography 30(2):210-220. https://doi.org/10.1177/0309133309339563.

Laliberte, A. S., and A. Rango. 2009. Texture and scale in object-based analysis of subdecimeter resolution unmanned aerial vehicle (UAV) imagery. IEEE Transactions on Geoscience and Remote Sensing 47(3):761-770. https: / / doi.org/ 10.1109/TGRS.2008.2009355.

Ludwig, J. A., and D. J. Tongway. 1995. Spatial organisation of landscapes and its function in semi-arid woodlands, Australia. Landscape Ecology 10(1):51-63. https://doi.org/10.1007/BF00158553.

Ludwig, J. A., B. P. Wilcox, D. D. Breshears, D. J. Tongway, and A. C. Imeson. 2005. Vegetation patches and runofferosion as interacting ecohydrological processes in semiarid landscapes. Ecology 86(2):288-297. https://doi.org/ 10.1890/03-0569.

Morales, J. M., y S. P. Ellner. 2002. Scaling up animal movements in heterogeneous landscapes: the importance of behavior. Ecology 83(8):2240-2247. https:/ /doi.org/10.1890/0012-9658(2002)083[2240:SUAMIH]2.0.CO;2.

Ormaechea, S. G., P. L. Peri, P. A. Cipriotti, and R. A. Distel. 2019. El cuadro de pastoreo en los sistemas extensivos de Patagonia Sur. Percepción y manejo de la heterogeneidad. Ecología Austral 29:174-184. https://doi.org/10.1890/ 0012-9658(2002)083[2240:SUAMIH]2.0.CO;2.

Paruelo, J. M., H. E. Epstein, W. K. Lauenroth, and I. C. Burke. 1997. ANPP estimates from NDVI for the central grassland region of the United States. Ecology 78(3):953-958. https://doi.org/10.1890/0012-9658(1997)078[0953: AEFNFT]2.0.CO;2.

Paruelo, J. M., R. A. Golluscio, J. P. Guerschman. A. Cesa, V. V. Jouve, and M. F. Garbulsky. 2004. Regional scale relationships between ecosystem structure and functioning. The case of the Patagonian steppes. Global Ecology and Biogeography 13(5):385-395. https:/ / doi.org/10.1111/j.1466-822X.2004.00118.x.

Rango, A., A. Laliberte, C. Steele, J. E. Herrick, B. Bestelmeyer, T. Schmugge, A. Roanhorse, and V. Jenkins. 2006. Using unmanned aerial vehicles for rangelands: current applications and future potentials. Environmental Practice 8(3):159-168.

Rango, A., A. Laliberte, J. E. Herrick, C. Winters, K. Havstad, C. Steele, and D. Browning. 2009. Unmanned aerial vehicle-based remote sensing for rangeland assessment, monitoring, and management. Journal of Applied Remote Sensing 3(1):033542. https:/ /doi.org/10.1017/S1466046606060224.

Reiche, J. L. R., A. L. Mitchell, J. Verbesselt, D. H. Hoekman, J. Haapaintner, J. M. Kellndorfer, A. Rosenqvist, E. A. Lehmann, C. E. Woodcock, and F. M. Seifert. 2016. Combining satellite data for better tropical forest monitoring. Nature Climate Change 6(2):120. https://doi.org/10.1038/nclimate2919.

Sarker, L. R., and J. E. Nichol. 2011. Improved forest biomass estimates using ALOS AVNIR-2 texture indices. Remote Sensing of Environment 115(4):968-977. https:/ / doi.org/10.1016/j.rse.2010.11.010.

Siffredi, G. L., F. Boggio, H. Giorgetti, J. Ayesa, A. Kröpfl, and M. Álvarez. 2013. Guía para la Evaluación de Pastizales para las áreas ecológicas de Sierras y Mesetas Occidentales y de Monte de Patagonia Norte - 2da ed. Ediciones INTA, Bariloche. Pp. 69.

Tralli, D. M., R. G. Blom, V. Zlotnicki, A. Donnellan, and D. L. Evans. 2005. Satellite remote sensing of earthquake, volcano, flood, landslide and coastal inundation hazards. ISPRS Journal of Photogrammetry and Remote Sensing 59(4):185-198. https://doi.org/10.1016/j.isprsjprs.2005.02.002. 